This item was submitted to Loughborough's Research Repository by the author.

Items in Figshare are protected by copyright, with all rights reserved, unless otherwise indicated.

\title{
Materials and processes issues in fine pitch eutectic solder flip chip interconnection
}

PLEASE CITE THE PUBLISHED VERSION

PUBLISHER

(C) IEEE

VERSION

VoR (Version of Record)

\section{LICENCE}

CC BY-NC-ND 4.0

\section{REPOSITORY RECORD}

Liu, Changqing, M.W. Hendriksen, David A. Hutt, Paul P. Conway, and David C. Whalley. 2019. "Materials and Processes Issues in Fine Pitch Eutectic Solder Flip Chip Interconnection". figshare.

https://hdl.handle.net/2134/4210. 
This item was submitted to Loughborough's Institutional Repository (https://dspace.lboro.ac.uk/) by the author and is made available under the following Creative Commons Licence conditions.

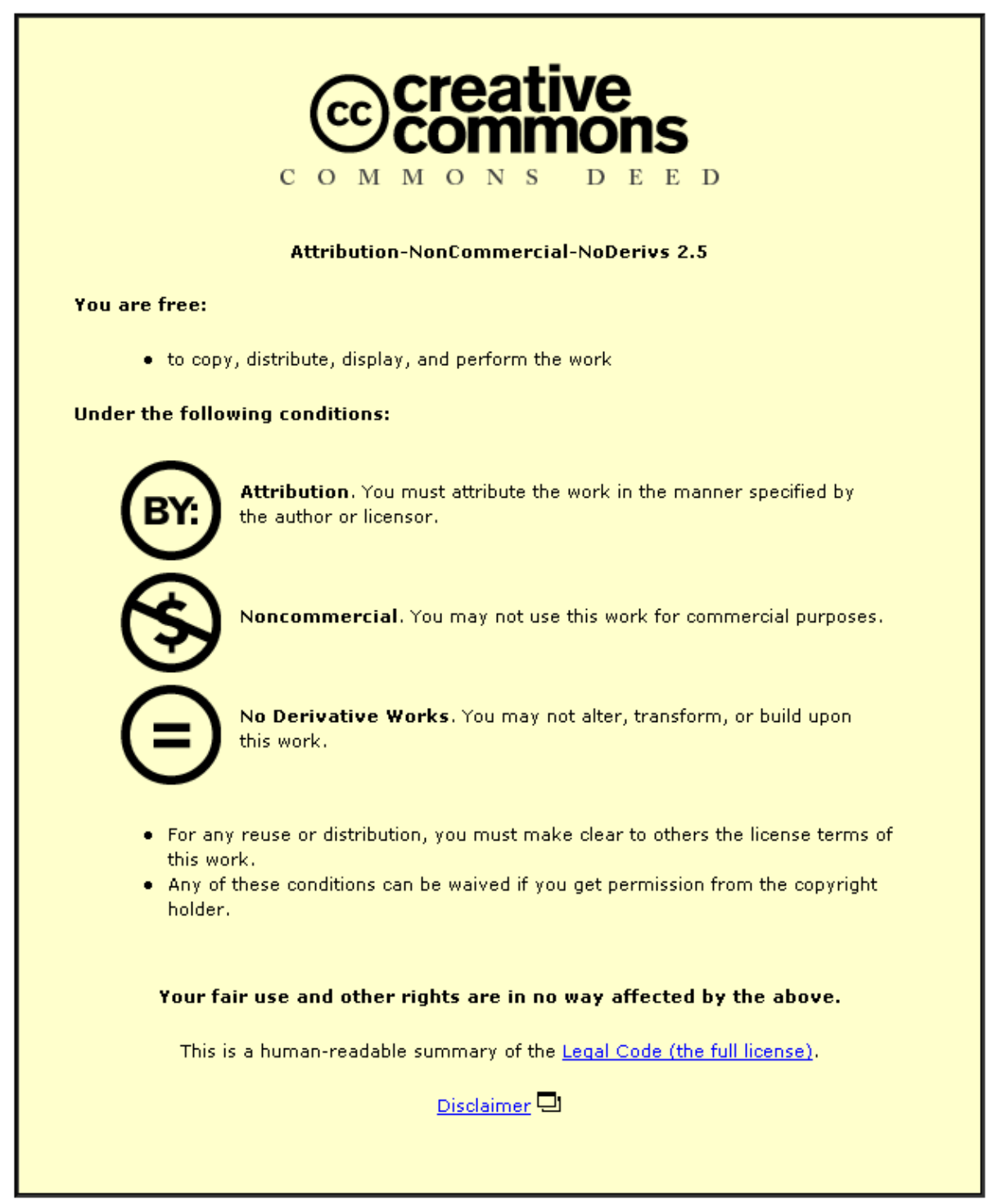

For the full text of this licence, please go to: http://creativecommons.org/licenses/by-nc-nd/2.5/ 


\title{
Materials and Processes Issues in Fine Pitch Eutectic Solder Flip Chip Interconnection
}

\author{
C. Liu ${ }^{\dagger}$, M.W. Hendriksen", D.A. Hutt, P.P. Conway, and D.C. Whalley \\ Wolfson School of Mechanical and Manufacturing Engineering \\ Loughborough University, Loughborough, Leics, LE11 3TU, UK \\ *Manufacturing Technology Group, Celestica Limited, \\ West Avenue, Kidsgrove, Stoke-on-Trent, Staffordshire, ST7 1TL, UK.
}

${ }^{\dagger}$ Corresponding Author: C.Liu@Lboro.ac.uk

\begin{abstract}
New product designs within the electronics packaging industry continue to demand interconnects at microscopic geometry, both at the Integrated Circuit (IC) and supporting board level, thereby creating numerous manufacturing challenges. Flip Chip On Board (FCOB) applications are currently being driven by competitive manufacturing costs and the need for higher volume and robust production capabilities. One of today's low cost FCOB solutions has emerged as an extension of the existing infrastructure for Surface Mount Technology (SMT) and combines an Under Bump Metallisation (UBM) with a stencil printing solder bumping process, to generate mechanically robust joint structures with low electrical resistance between chip and board. Although electroless Ni plating of the UBM, and stencil printing for solder paste deposition, have been widely used in commercial industrial applications, there still exists a number of technical issues related to these materials and processes as the joint geometry is further reduced. This paper reports on trials with electroless $\mathrm{Ni}$ plating and stencil paste printing and the correlation between process variables in the formation of bumps and the shear strength of such bumps at different geometries. The effect of precise control of the tolerances of squeegees, stencils and wafer fixtures was examined to enable the optimisation of the materials, processes and tooling for reduction of bumping defects.
\end{abstract}

\section{Introduction}

Compared with peripheral leaded package styles Ball Grid Array (BGA) and Chip Scale Packaging (CSP) formats provide increased circuit density capability coupled with a reduction in real estate coverage on the supporting board. However, as the inexorable drive towards miniaturisation and higher operating speeds continues, the need to completely eliminate even the minimum of chip packaging becomes evermore critical. Flip chip interconnection involves the assembly of naked, unpackaged chips directly to a supporting board, requiring products to be manufactured with solder joints at geometries similar to those of the semiconductor chips. Further reduction in the scale of flip chip geometries is expected, to ensure the technology keeps abreast of future product applications and IC designs [1,2]. Such demands are also reflected at the board level, where microvia

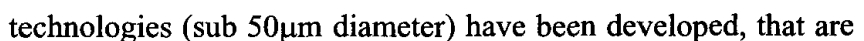
capable of supporting FCOB interconnection [3].

Various hybrid processing techniques have been explored and adopted within the electronics manufacturing industry in order to provide FCOB solutions [4-7]. Electroplating, evaporation, solder jetting, stud bumping, stencil printing and "squeegee bumping" [7] have been employed, with each having its own merits, but their technological capability in terms of joint geometry, metallurgy, reliability, and processing cost (equipment, production yield) are critical factors to be considered. Extending existing SMT, i.e. process capabilities, equipment and soldering materials, offers a cost-effective solution for flip chip interconnection that is attractive to manufacturers having an existing SMT infrastructure. Solder joints formed by reflow of a bumped chip onto a supporting board (usually with the assistance of a flux) are capable of achieving flip chip interconnects by coupling the stencil printing technique with an electroless $\mathrm{Ni}$ Under Bump Metallisation (UBM): a cost-effective approach for providing a wettable surface finish to the $\mathrm{Al}$ bondpads on the chip. The electroless Ni-P UBM process has already been thoroughly investigated [8-11] and the existing industrial $\mathrm{Ni}-\mathrm{P}$ plating processes and bath formulations for providing corrosion or wear resistance to engineering components have proven unsuitable for the UBM of fine pitch flip chip, which requires selective deposition onto the bond pads. Although improvements to this process have been made by several groups, and potentially commercialised to achieve a quality UBM satisfying a variety of wafer specifications and manufacturing details (e.g. pad registration, passivation etc.), there still exists a number of issues regarding the plating quality and technical specifications with respect to the initial bondpad characteristics (e.g. Al alloy composition, microstructure, thickness, properties and passivation defects).

The materials and processing variables in stencil printing also critically affect the quality and yield of solder deposition to produce consistent, reproducible and uniform bumps for fine pitch flip-chip prior to final assembly [12-20]. The Ishikawa cause-and-effect diagram generated by Pan et al. [14] summarises these variables. There are eight major categories identified (operator, environment, printing parameter, printer, stencil, wafer, squeegee and solder paste) that could influence the solder paste printing. Pan et al showed that, apart from the rigid control of the parameters related to the materials and systems 
used, the operator's skills and experience need to be included. In this paper, FCOB trials have been undertaken with fine pitch flip chips (in the range of 300 to $90 \mu \mathrm{m}$ ) with both peripheral and full array bond pad layouts. The issues related to materials and processing variables are addressed to provide guidance in the further enhancement of $\mathrm{FCOB}$ for high volume production.

\section{Experimental Details}

\section{A. Flip Chips for Trials}

Two types of test chip, having different feature dimensions, were used to investigate the effects of size in relation to the materials and processes. Test chips were processed in a 4 inch wafer format prior to dicing for bump analysis and assembly. Wafer type A (Figure 1a) was a peripheral I/O daisy chain design with $\mathrm{Al}-\mathrm{Cu}(\mathrm{Cu} 1 \mathrm{Wt} \%)$ alloy bondpads $(3 \mu \mathrm{m}$ thickness) on pitches of $225 \mu \mathrm{m}$ and $300 \mu \mathrm{m}$. The circular openings in the silicon nitride passivation over the bondpads had a diameter of $75 \mu \mathrm{m}$. The type A chips were $6 \mathrm{~mm}$ square with a thickness of $500 \mu \mathrm{m}$.

Wafer type B (Figure 1b) included chip designs with both peripheral and full area array patterns of pure $\mathrm{Al}$ bondpads $(1 \mu \mathrm{m}$ thickness). For the purposes of this experimental evaluation, chips with an $\mathrm{I} / \mathrm{O}$ pitch ranging from $90 \mu \mathrm{m}$ to $150 \mu \mathrm{m}$, in a daisy chain format, were used. The bondpads had a circular passivation opening of $50 \mu \mathrm{m}$ for the $90 \mu \mathrm{m}$ pitch, but $60 \mu \mathrm{m}$ for the other pitches. The type B wafer was laid out as an array of $12 \times 12 \mathrm{~mm}$ repeated patterns, where each $12 \times 12 \mathrm{~mm}$ die was subdivided into a further 16 smaller $3 \times 3 \mathrm{~mm}$ die areas. Figure $1 \mathrm{~b}$ shows the bondpads on these $3 \mathrm{~mm}$ square sub-die which are laid out on four different pitches. Each pitch was laid out as a peripheral design, an array in a square pattern and a staggered array where the bumps were packed the closest that they could be for that pitch. Table 1 summarises the details of the two types of wafer used for this work.

Table 1. Comparison of the two types of wafer used

\begin{tabular}{ccc} 
& for the trials & \\
\hline Wafer & Type A & Type B \\
\hline Bondpad material & $\mathrm{AlCu}(1 \mathrm{wt} \% \mathrm{Cu})$ & Pure $\mathrm{Al}$ \\
Bondpad thickness & $3 \mu \mathrm{m}$ & $1 \mu \mathrm{m}$ \\
Passivation & $\mathrm{Si}_{3} \mathrm{~N}_{4}$ & $\mathrm{SiO}_{2}$ \\
Defects on & $\mathrm{None}$ & Fine particles and \\
passivation & & pits \\
Die size & $6 \times 6 \mathrm{~mm}$ & $3 \times 3 \mathrm{~mm}$ \\
Pitch & $225,300 \mu \mathrm{m}$ & $90,100,125,150 \mu \mathrm{m}$ \\
Bondpad shape & Octagonal & Octagonal \\
Bondpad opening & $75 \mu \mathrm{m}$ circular & $50,60 \mu \mathrm{m}$ circular \\
Bondpad layout & Peripheral & Peripheral, full array \\
\hline
\end{tabular}

B. Under Bump Metallisation (UBM) and Solder Bumping Trials Both types of wafer were processed to generate an UBM layer on the bondpads for subsequent solder bump formation, using an electroless nickel plating process, developed previously [10, 2122]. The process included pretreatment and activation of the $\mathrm{Al}$ bondpads by a single or double zincate treatment followed by plating in an acidic hypophosphite bath that deposited a layer of Ni-P containing 4-5 Wt\% $\mathrm{P}$.
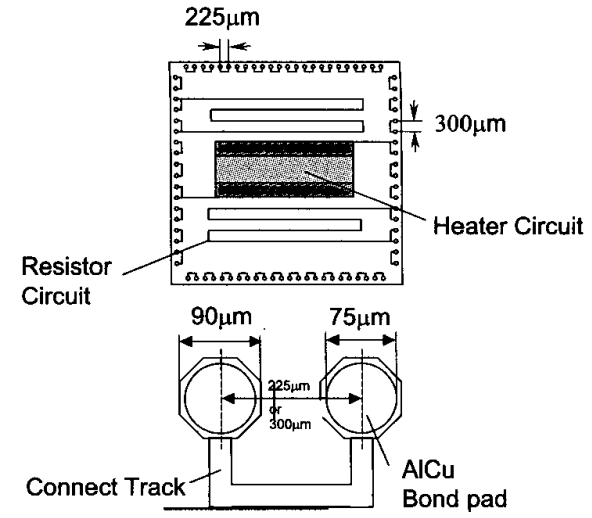

a) Wafer Type $A$

$12 \mathrm{~mm}$
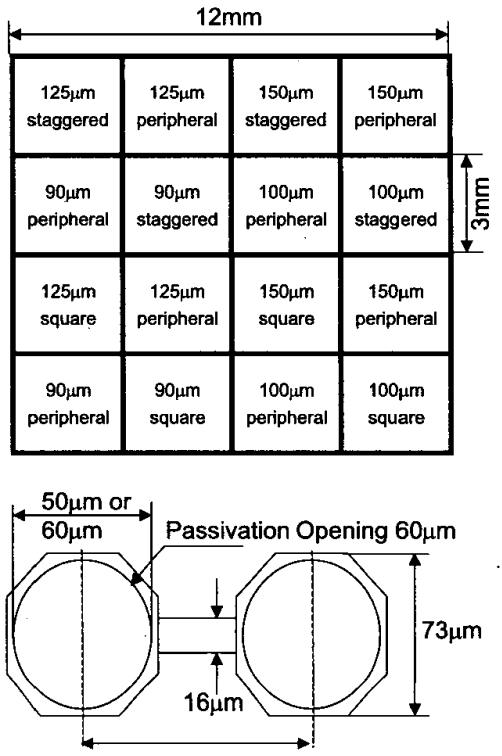

Pitch: $90,100,125$, or $150 \mu \mathrm{m}$

b) Wafer Type B

Figure1. Details of test chip designs: pad pitch, layout, materials and passivation opening

Following the electroless Ni UBM plating, solder paste deposits were created by stencil printing onto the bondpads to form eutectic $\mathrm{Sn} / \mathrm{Pb}$ bumps for subsequent reflow soldering. A recently developed paste that contained an $89 \mathrm{wt} . \%$ content of $\mathrm{SnPb}$ eutectic solder alloy particles (diameter 5-15 $\mu \mathrm{m}$ ) and formulated with three different flux systems (Rosin Mildly Activated (RMA), no-clean (NC) and water soluble (WS)) was used for the printing trials. Stencil aperture sizes in the range of $175 \mu \mathrm{m}$ to a minimum of $75 \mu \mathrm{m}$ in diameter were assessed with two electroformed Ni stencils that were $50 \mu \mathrm{m}$ and $75 \mu \mathrm{m}$ thick. Both metal and rubber squeegees were employed to compare their effects. The length of the metal blade was $300 \mathrm{~mm}$, and the 
ruber squeegees are $168 \mathrm{~mm}$ long and $7 \mathrm{~mm}$ thick. Using a DEK 265 printing machine, stencil printing parameters such as squeegee speed and applied pressure were optimised to achieve suitable quality solder paste deposits for both the A and B type wafers. The printing speed: $10 \mathrm{~mm} \mathrm{~s}^{-1}$; snap off (separation gap between stencil and wafer surface): $0.00 \mathrm{~mm}$; normal load on squeegee: $30-80 \mathrm{~N}$; separation speed: $0.5-2.0 \mathrm{~mm} . \mathrm{s}^{-1}$.

Finally, reflow of the paste deposits in an $\mathrm{N}_{2}$ inert atmosphere was carried out to form the solder bumps. A Scanning Electron Microscope (SEM) with Energy Dispersive Analysis of X-rays (EDX) was utilised to investigate the surface morphology and for materials analysis.

\section{Laser Surface Profiling}

Since the wafer was too fragile to be handled by the standard printed circuit board carrier, a wafer fixture (or 'holder') was needed to support the wafer during printing. Two wafer fixtures (I and II) were used for the trials, which had different tolerances for the recessed pocket where the wafer was held by vacuum. Fixture I was machined from an aluminium alloy with a recessed circular pad made from porous ceramic. Fixture II was machined from mild steel with a precision recessed pocket with minimum surface variation. The surface planarity of the wafer when held in the pocket using both fixtures was evaluated using an ISO Surf laser surface profiler, which utilised a Rodenstock RM600 laser stylus capable of non-contact measurement between $0.01 \mu \mathrm{m}$ and $600 \mu \mathrm{m}$.

\section{Bump Micro-shear Testing}

A micro-shear strength study of the mechanical integrity of the eutectic $\mathrm{Sn} / \mathrm{Pb}$ bumps was conducted using a Dage Series $4000^{\circ}$ Multi-purpose Bond Tester with a BS250 Ball Shear cartridge. This low deflection cartridge enabled precision shearing at preset heights above the chip surface. The width of the shear tool was $100 \mu \mathrm{m}$, sufficiently wide to cover the bump diameter but not so wide as to interfere with adjacent bumps during the shear testing. A shear speed of $100-300 \mu \mathrm{m} / \mathrm{sec}$ and shear height of $25-$ $50 \%$ of the bump height were employed. During each test, the peak shear force and the corresponding displacement of the shear tool through the bump structure were recorded. For each shear test protocol, 20 solder bumps were sheared from individual chips which were randomly chosen from each test wafer.

\section{Results and Discussion}

\section{A. Under Bump Metallisation}

The Under Bump Metallisation (UBM) provides a solderable surface as well as protection for the $\mathrm{Al}$ pads from flux and solder dissolution during the solder reflow processes. A process that has received considerable interest as a maskless low cost wafer UBM technique is electroless nickel deposition, which is also suitable for large volume production [12]. However, plating defects can occur when finer pitch chips are processed, which are related to the pad microstructure and plating process variables. Several issues in connection with the pretreatment of Al bondpads are highlighted here including the influence of the first sodium hydroxide etching step and the zincate activation processe. Figures 2 a-c show the surface morphology of the $\mathrm{Al}$ pads on wafer type $\mathrm{B}$ after pre-etching in $5 \% \mathrm{NaOH}$ solution for 10,20 , and 30 seconds respectively. Clearly, due to the localised preferential etching, the $\mathrm{Al}$ pads became more porous after 30 seconds etching, which led to poor Ni-P morphology in the subsequent plating. Figure $2 \mathrm{~d}$ shows an EDX analysis from these etched surfaces. A dramatic decrease in their Al content was seen for 30 s etching, indicating that damage to the pads had occurred.
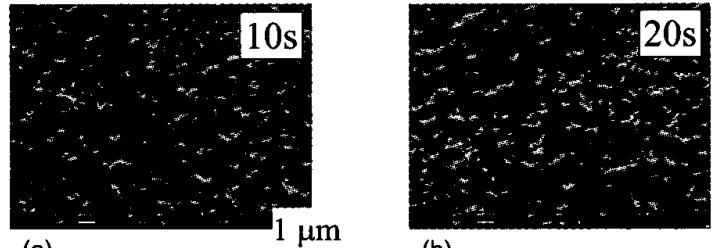

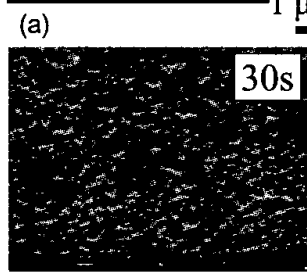

(c)

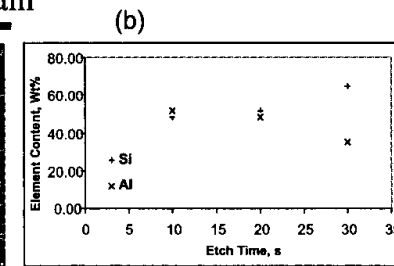

(d)
Figure 2. Etching of Al pads on wafer $B$ in $5 \%$ $\mathrm{NaOH}$ solution: SEM surface morphology after a) $10 s, b) 20 s, c) 30 s$, and the EDAX elemental content analysis d)

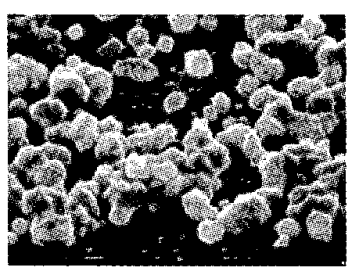

(a) 20 s single zincate

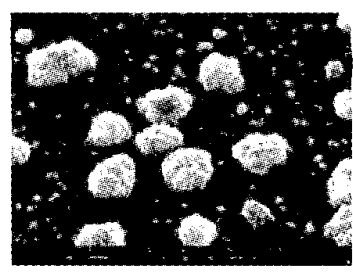

(b) 20 s double zincate
Figure 3. Zincate treatment of Al pads on wafer B: a) $20 \mathrm{~s}$ single zincate; b) $20 \mathrm{~s}$ double zincate, following 20 s etch in $5 \% \mathrm{NaOH}$

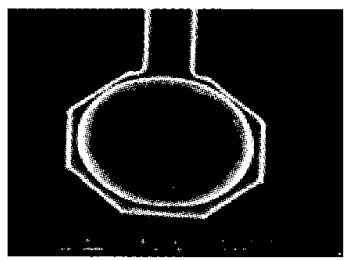

(a)

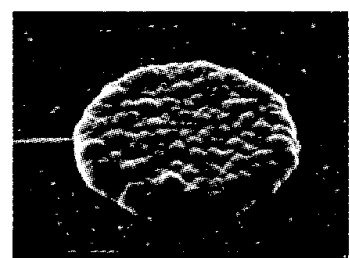

(b)
Figure 4. Electroless Ni-P UBM bump formation: a) Ni-P bump on pads of wafer type A; b) Ni-P bump on pads of wafer type $B$ 
The zincation process, which is conventionally used to activate the $\mathrm{Al}$ pads prior to $\mathrm{Ni}$ deposition, may also be thinning the $\mathrm{Al}$ pads due to the highly alkaline characteristics of the zincate solution. This could substantially reduce the interfacial bonding strength (adhesion) of the deposited Ni layers [10]. Figures 3a, and $3 \mathrm{~b}$ are SEM micrographs of the Al pads of wafer type B after 20 seconds single and double zincation, respectively. In comparison with the porous Al pads from single zincation (Figure $3 \mathrm{a}$ ), the $\mathrm{Al}$ pads after double zincation had been entirely removed (Figure $3 \mathrm{~b}$ ). This led to a radical reduction of the adhesion for the $\mathrm{Ni}$ layer [10]. Furthermore, the electrical resistance of the contact increased dramatically due to the thinning of the Al pads. For wafer type A, the thicker Al-Cu alloy pads allowed a wider processing window for etching and zincation to produce a finer and smoother zincate layer prior to $\mathrm{Ni}$ plating. Figures $4 \mathrm{a}-$ and $4 \mathrm{~b}$ show the typical surface morphology of the Ni-P coating on the bondpads of wafer $\mathrm{A}$ and $B$, respectively. A number of issues related to the type $B$ wafer and process specifications were identified for finer pitch flip chips, as shown in Figure 5 - an SEM image of a $5 \mu \mathrm{m}$ Ni-P UBM for a $100 \mu \mathrm{m}$ pitch staggered full array chip. The defects observed in the passivation resulted in the deposition of $\mathrm{Ni}$ nodules over tracks and between pads. This may cause shortcircuits between pads; therefore, caution must be taken to avoid such faults at wafer manufacture to eliminate defects in passivation and to ensure accurate registration of pad openings.

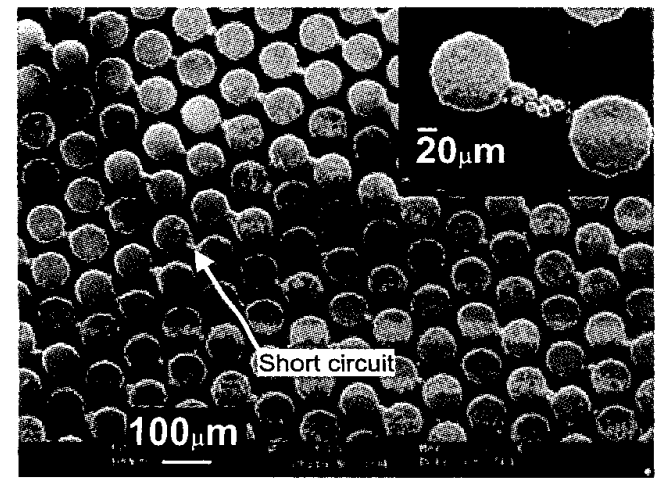

Figure 5. Electroless Ni-P plating defect identification: $5 \mu \mathrm{m}$ thick Ni-P layer on $100 \mu \mathrm{m}$ pitch staggered full array chip

\section{B. Stencil Solder Bumping of Flip Chips}

1. Solder paste deposition by stencil printing

Production of consistent, reproducible and uniformly distributed paste deposits over an entire wafer by stencil printing presents numerous challenges in finer pitch flip-chip applications. The solder paste used is composed of solder alloy particles, flux, viscosity controlling agents and a solvent system. Modelling and experimental work has demonstrated that the ratio of the aperture size to the solder particle diameter should be around five [20]. Depending upon the pitch size of the flip chips, a solder paste containing fine particles (e.g. $5-15 \mu \mathrm{m}$ ) is therefore usually required to enable sufficient stencil aperture fill and acceptable release characteristics. In the printing process, solder paste sheared off by a squeegee blade rolls and subsequently fills the apertures in the stencil ahead of the squeegee as it moves over the stencil. On completion of the print stroke, the wafer is separated from the stencil, generating freestanding paste deposits on the bondpads beneath the stencil. Typical printing defects include bridging of adjacent pads, slumping, poor shapedefinition and skipping (insufficient or no solder deposited) [19]. Optimised printing needs to consider variables including: paste rheology (e.g. viscosity); squeegee pressure and speed; stencil separation speed; print direction and environmental considerations such as temperature and humidity. According to Zou et al [17], the print temperature and humidity could significantly affect the printing quality using the squeegee method; it is therefore advantageous to use an enclosed, environmentally controlled print system [17]. The printing trials in this work were however performed in uncontrolled ambient environment on two types of wafer (A and B) to investigate both the attributes and consistency of the paste deposits, without consideration of the external environment (e.g. temperature and humidity and air flow). The critical factors affecting paste flow during the printing were thought to be aspect and area ratio, with paste transfer efficiency being improved if the aspect and area ratio were higher than 1.25 and 0.6 , respectively [24]. There has been some experimental work combined with computational study (i.e. CFD approaches) to understand the printing process and the variables at macroscopic and microscopic scales [20, 23, 24].

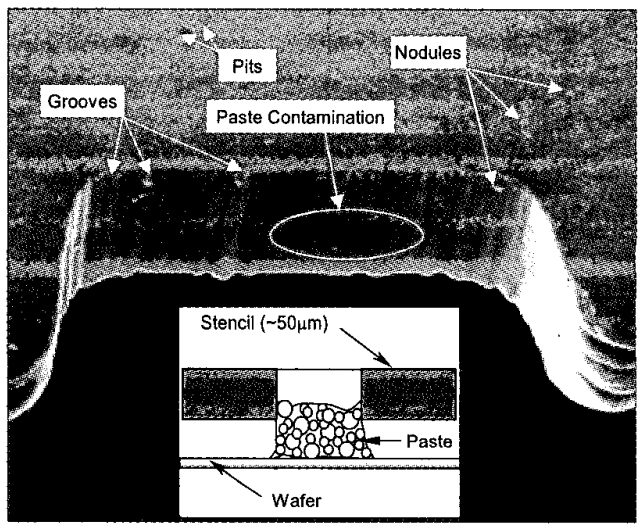

Figure 6. Stencil manufacture and definition: SEM image of the aperture wall texture from a nickel electroformed stencil cross section

Figure 6 shows a SEM view of a $100 \mu \mathrm{m}$ square aperture from the $\mathrm{Ni}$ electro-formed stencil. A number of features are apparent on the stencil surface (e.g. pits, nodules and scratches), and along the wall of the apertures (e.g. grooves). As these features were equivalent to the size of particles in the paste, it is likely that filling of the aperture was affected by the interactions between paste and stencil. Macroscopic studies on the bulk motion of paste ahead of a squeegee have indicated Non-Newtonian behaviour during the rolling of the paste and numerous process 
parameters may therefore play important roles in determining the paste deposition [23]. Meanwhile, the microstructural dynamics of individual particles suspended in the carrier fluid could be critical to the printing consistency and quality [20]. In this study, the wave-like groove texture along the aperture wall (see Figure 6) is likely to have affected the flow, filling and release behaviour of the paste. In particular, adjacent to the corners of square apertures, the paste packing and subsequent release during the 'snap-off' (separation of stencil from wafer) can be substantially affected as indicated by microstructural modelling by $\mathrm{He}$ et al [20]. The stencil surface texture that contained features (e.g. pits and inclusions) at the microscopic scale can also influence the rolling of the paste and the interaction of paste with the stencil, which also impacts on the print quality. The relationship between the motion of solder particles and the paste rheology and the tendency for paste to adhere to the aperture walls during stencil withdrawal requires further study into the microstructure of paste transfer dynamics. However, the behaviour of a dense suspension at a plane wall boundary is different to that at the interior. Therefore, the paste deposition can be largely determined by the localised properties and interactions between the solder paste and stencil wall texture [23].

2. Tolerance of tooling (stencil, squeegees and wafer fixture) in fine pitch solder paste printing

The stencil used for printing plays a significant role in the quality and yield of solder paste deposition. Currently, stencils for SMT assembly are usually fabricated by chemical etching, $\mathrm{Ni}$ electroforming, or laser cutting processes. The materials used to make a stencil should meet various requirements in terms of their processability, durability, plastic/elastic deformation properties, wear and corrosion resistance, and cost effectiveness. Electrochemical Ni formed stencils have been often used for fine pitch flip chip wafer bumping (e.g. for the $\sim 100 \mu \mathrm{m}$ pitch on wafer type B) due to their high hardness, excellent creep and fracture resistance and rapid manufacturability. However, the challenge still remains to reduce the manufacturing costs and to optimise the microstructure of the surface finish and precision aperture definition [18]. In particular, for finer pitch chips, the relationship between the aperture shape and size, and the aspect and area ratio has to be considered to achieve the highest packing efficiency. The stencil surface friction and elastic and plastic characteristics are also important parameters to achieve high alignment accuracy and a suitable 'snap-off' characteristic.

Squeegees are the blades used to shear and propel the solder paste to fill the apertures in the stencil. The contact between squeegees and the stencil surface, and paste rolling due to the shear process, were both found to significantly affect the final bumping quality (consistency and defect rates). The squeegee materials and properties (e.g. hardness, stiffness, and straightness) are of particular concern. Printing trials in this study showed that the quality and yield of paste deposits were dramatically improved with a rubber squeegee, in comparison to a metal squeegee. To explain this, Figure $7 \mathrm{a}$ and $7 \mathrm{~b}$ schematically illustrate the deformation of a stencil with two types of squeegees: stainless steel and rubber, respectively. The closer contact along the curved stencil surface that is attributed to the better elastic characteristics of rubber materials results in a narrower crevice between the squeegee and stencil, whilst the stainless steel squeegees were unable to co-locate the deformation with the stencil surface, so that larger contact gaps resulted. The larger the crevice, the lower the packing efficiency obtained, because of the localised lower levels of shearing and pressure. Therefore defects such as partial or incomplete deposits (skipping) and missing bumps were observed after the stencil was removed. Visual inspection confirmed that the distribution of the paste deposits when using metal squeegees was less uniform, and many missing or skipped bumps occurred.

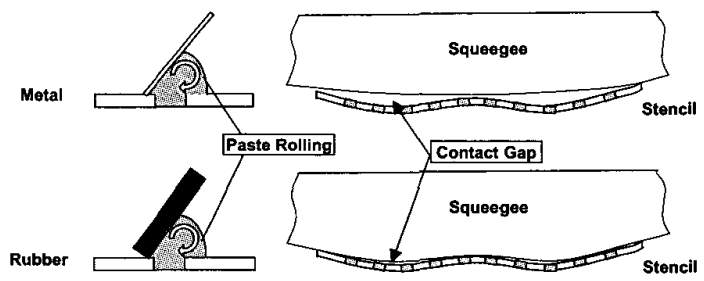

Figure 7. Squeegees in action to roll the paste and fill the stencil aperture
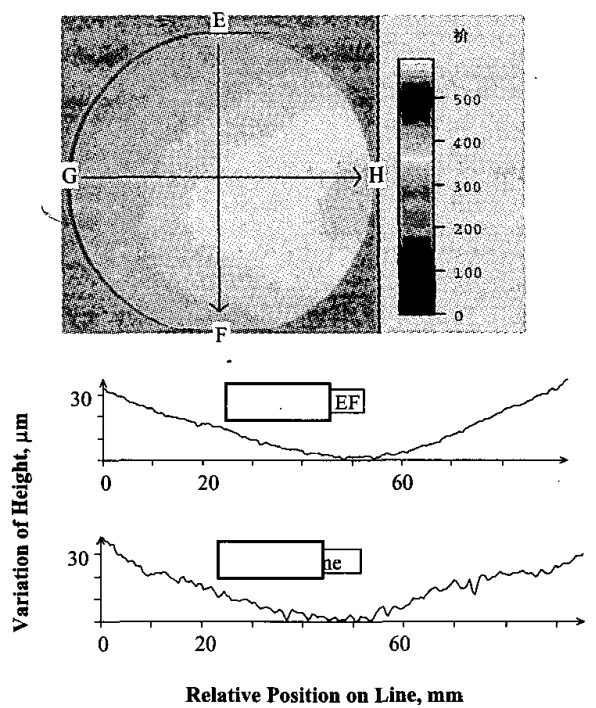

Figure 8. Laser surface imaging profile of wafer fixture I: Surface variation of wafer in pocket drawn down by vacuum

The dimensional tolerance or accuracy of the wafer fixture (holder) is also critical to the printing quality (e.g. consistency) and yield. Two types of wafer fixtures (I and II) were used in this work to investigate the effect of their surface co-planarity tolerance. Figure 8 provides the laser surface topography when the wafer was drawn into the pocket of fixture $I$ by vacuum during the printing process. The line profiles EF and $\mathrm{GH}$ from 
the scans show a variation in height of over $40 \mu \mathrm{m}$, measured from the edge to the centre of the wafer, owing to the poor planarity of the pocket surface. Zou et al [17] proposed the estimation of substrate (e.g. wafer) distortion degree using $\mathrm{H} / \mathrm{L} \%$, where $\mathrm{H}$ is the maximum vertical variation due to bending, $\mathrm{L}$ the substrate length or diameter. Accordingly, using fixture I the wafer distortion degree is estimated to be $0.04 \%$ for the 4 inch wafers that were used $\left.(40 / 101600)^{*} 100 \%=0.039 \%\right)$. This is well below the critical value of $0.1 \%$ that was proposed by Z bu et al to enable acceptable quality by squeegee printing in the case of PCBs with pitch size bigger than $300 \mu \mathrm{m}$. However, in this study, for printing on wafers with pitch size smaller than $300 \mu \mathrm{m}$, the trials showed that printing with rubber squeegee was unable to cope with distortions as small as $0.04 \%$ using fixture I. This resulted in a solder paste 'smear' area that appeared near the centre of the wafer after printing, and consequently, the occurrence of a number of print defects such as slumping, skipping, missing or displaced bumps where the paste 'smear area' was observed.

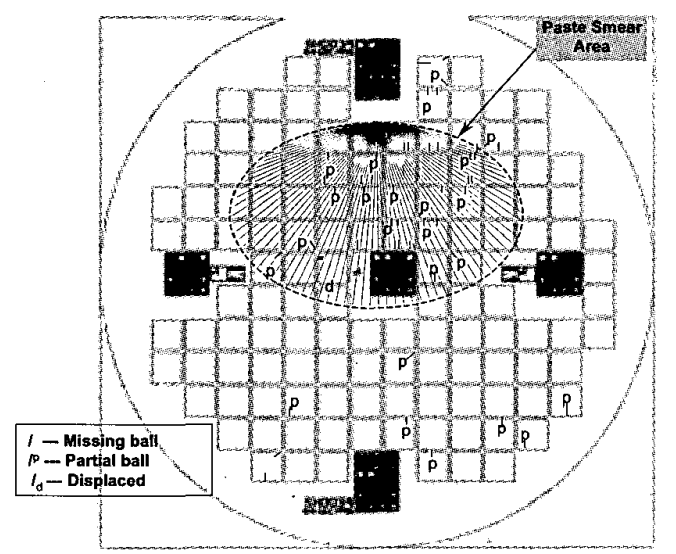

Figure 9. Evaluation of bumping by stencil printing on wafer type A with wafer fixture I: A smear paste area was identified causing poor quality of paste deposition

Figure 9 shows a typical result of the evaluation selected from a number of trials on wafer type A. This indicates that the rigid wafer fixture is required to ensure the flatness of the wafer surface to be printed. Using wafer fixture II, the resulting variation on the wafer when it was drawn down in the pocket by vacuum was around $5 \mu \mathrm{m}$ (see the line profiles of EF and GH in Figure 10). This variation can be converted into a distortion degree of approximately $0.005 \%$. Unsurprisingly, when using fixture II, there was no observable 'smear' area after printing, printing trials showed an excellent quality and uniformity of paste deposit distributed throughout the entire wafer surface, with a dramatic reduction of the defects. Improvement of printing quality due to the smaller distortion of the wafer surfaces to be printed is likely to lead to a significant increase of paste packing efficiency and a neater release motion of the paste from the apertures. The stencil conforming closely to the wafer surface resulted in uniform squeegee pressure and a controlled "snapoff" when withdrawing the stencil from the wafer surface, enabling the paste deposits to be released uniformly over the entire wafer surafce. The smeared paste area occurred where the squeegees could not remove the paste from the depressed areas, such that the paste residues remained on the stencil surface. In these areas, on withdrawal of the stencil, the paste in the apertures could be completely or partially lifted up along with the paste residues on the stencil, thereby causing slumping, skipping and missing or displaced bumps. In addition, the paste packing efficiency was significantly decreased due to less shear and squeegee pressure in the depressed areas.
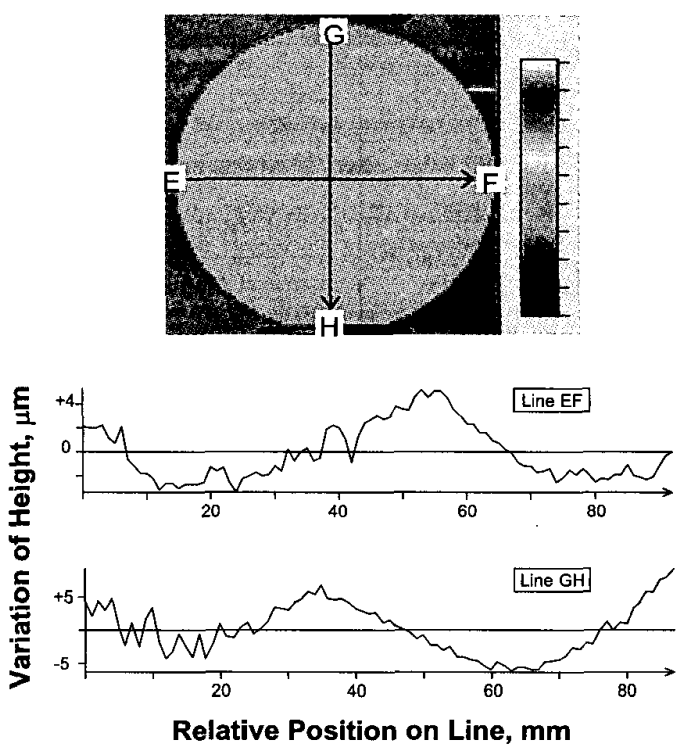

Figure 10. Laser surface imaging profile of wafer fixture II: Surface variation of wafer in pocket drawn down by vacuum

\section{Formation and Shear Strength of Solder Bumps}

After a reflow process in a nitrogen atmosphere the solder paste deposits formed solid solder bumps. Figure 11a shows the solder bumps for a $150 \mu \mathrm{m}$ pitch full array chip, which included a bridging defect. This type of failure was the result of adjacent oversized deposits merging together during reflow when the pitch size was close to the pad openning. The small balls formed between the bumps in Figure 11a are thought to be formed at the defects on the passivation layer where the small Ni nodules were generated in the Ni UBM processes (Figure 5) and could later have become the sites for solder attachment. The microsectional image (Figure 11b) confirms the excellent wetting of solder to the Ni-P UBM and the formation of the intermetallics along the interface between the solder alloy and Ni-P layer, producing a typical bump with a $60 \mu \mathrm{m}$ height $80 \mu \mathrm{m}$ diameter at $150 \mu \mathrm{m}$ pitch. 


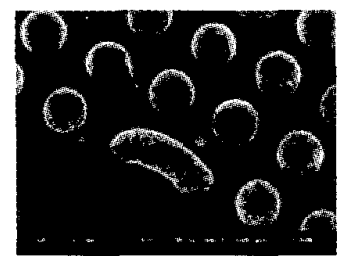

(a)

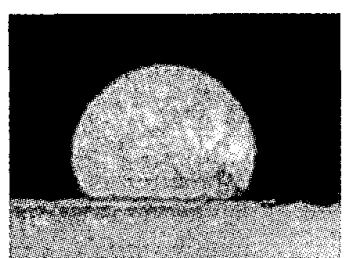

(b)
Figure 11. Solder bump formation: a) SEM micrograph of solder balls on Ni UBM of $150 \mu \mathrm{m}$ pitch; and b) Cross-sectional view of a $80 \mu \mathrm{m}$ diameter bump

Shear tests were carried out in this work to evaluate the mechanical strength of bumps, and to understand the failure modes. From previous BGA and CSP shear studies, and the lack of shear strength information at small-scale geometries, the shear study was conducted to understand the effects of testing parameters on bump integrity. Figures $12 \mathrm{a}$ and $12 \mathrm{~b}$ show the effects of both shear speed and shear height at $80 \mu \mathrm{m}$ and $100 \mu \mathrm{m}$ bump diameters, respectively. The error bars around the data points, for all the graphs in this text, represent one standard deviation. The results, for the varying bump diameters, indicate two trends clearly visible from the shear study. Firstly, increasing the shear speed yields apparently higher shear strengths for the bumps. Secondly, reducing the shear tool height also appears to

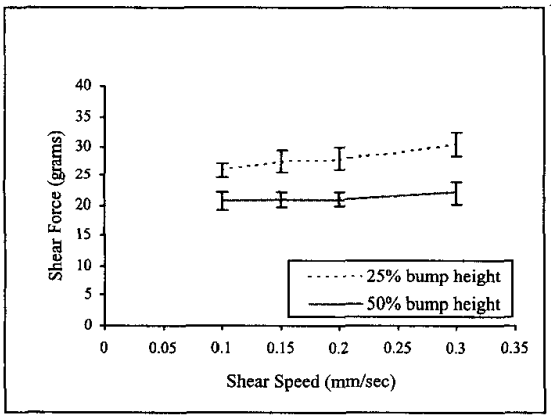

(a) $80 \mu \mathrm{m}$ bump diameter

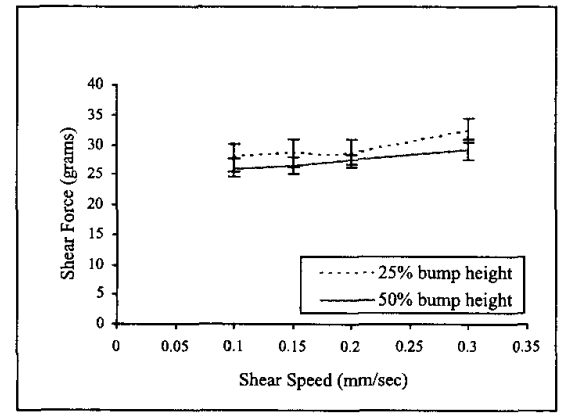

(b) $100 \mu \mathrm{m}$ bump diameter

Figure 12. Bump shear results: the effects of varying the bump diameter and shearing height increase the bump shear strength. The variation in shear height was investigated in light of the shear height tolerance specified within the JESD22-B117 standard, which states a maximum shear height of $25 \%$ of the bump height. These shear study trends reflect similar work reported by Huang et al [25], albeit at BGA geometries. Further shear testing was conducted at a shear speed of $150 \mu \mathrm{m} / \mathrm{sec}$ and corresponding height of $25 \%$. The average shear strength was found to be greater for the $100 \mu \mathrm{m}$ bump size $(28.6 \mathrm{~g} \pm 2.3 \mathrm{~g})$, compared to the $80 \mu \mathrm{m}$ size $(27.5 \mathrm{~g} \pm 1.8 \mathrm{~g})$. This is attributed to an increase in the sheared cross sectional area.

\section{Conclusions}

A number of technical issues related to the materials and process variables have been presented, in order to produce quality bumps and thus reliable solder joints for fine pitch FCOB interconnection. In electroless $\mathrm{Ni}$ plating for the UBM, the pretreatment steps including the etching (in $\mathrm{NaOH}$ ) and zincation, are critical to ensure a Ni-P layer with adequate adhesion to the $\mathrm{Al}$ pads and low electrical resistance. The elimination of $\mathrm{Ni}$ nodules generated at the defects in passivation is crucial to prevent bridging and as such wafer manufacture should ensure a defect free passivation with accurate registration of the pad openings.

The stencil printing trials identified issues of stencil fabrication (e.g. the need for high quality aperture definition), and dimensional tolerances of the squeegees and wafer fixtures used in printing. The filling, release and distribution characteristics of the paste material through the small apertures determine the quality and consistency of the bump formation. Therefore, not only the print parameters, but all of the related mechanical components (e.g. stencil, squeegees, and wafer fixture etc.) and their dimensional tolerances need to be carefully considered to achieve the maximum reduction of bumping defects. Significant reductions in solder bumping defects by stencil printing have been achieved by optimising the materials and processing variables in relation to the precise manufacture, definition, rigid design and control of the stencil apertures, wafer fixtures and squeegees. A Ni formed stencil with finely defined aperture geometries, coupled with the use of rubber squeegees, rigid wafer fixture and optimised printing parameters has been employed to produce consistent, reproducible and uniform paste deposits with high yields and quality for flip chip wafer bumping with the pitch size around $100 \mu \mathrm{m}$.

\section{Acknowledgements}

The authors would like to thank the EPSRC for financial support under Grant number GR/L61767. The technical support of Henkel Technologies, DEK Printing Machines is gratefully acknowledged. The authors would also like to thank Mr John Jones and Mr Jagpal Singh for their technical support in preparation and surface profiling of the new wafer fixture. 


\section{References}

1. Suhir, E, "Microelectronics and Photonics - the future", Microelectronics Journal, Vol. 31, Issue 11-12, 2000, pp.839-851.

2. Tummala, R, White, G, Sundaram, V, "SOP :Microelectronics Systems Packaging Technology for $21^{\text {st }}$ Century; Prospects and Progress", Proc $12^{\text {th }}$ IMAPS European Microelectronics \& Packaging Conference, Harrogate, UK, Jun 1999, pp.327-335.

3. Hendriksen, M.W, Frimpong, F.F, Ekere, N.N, "Interconnect Solutions for Advanced Area Array Packaging", Journal of Microelectronics International, Volume 16, Number 2, (Apr. 1999), pp.49-54.

4. Lau, J.H, Low Cost Flip Chip Assembly, McGraw-Hill (New York, 1995).

5. Kloeser, J, Heinricht, K, Kutzner, K, Jung, E, Ostmann, A, Reichl,H, "Fine Pitch Stencil Printing of $\mathrm{Sn} / \mathrm{Pb}$ and Lead Free Solder for Flip-chip Technology", IEEE Transactions on Components, Packaging, and Manufacturing Technology Part C, Vol.21, No.1, 1998, pp41-50.

6. Keser, L.A, Bajaj, R, Fang, T, "Redistribution and Bumping of a High I/O Device for Flip Chip Assembly", IEEE Transactions on Advanced Packaging, Vol. 23, No.1, 2000, pp3-8.

7. Lin, J.K, Fang, T, Bajaj, R, "Squeegee Bump Technology", IEEE Transactions on Components and Packaging Technology, Vol.25, No.1, 2002, pp38-44.

8. Hutt, D.A, S.H. Mannan, D.C. Whalley, and P.P.Conway, "A Maskless, Low-Cost, Multi-Chip-Module Assembly Process", Proceedings of the Pacific Rim/ASME International Intersociety Electronic and Photonic Packaging Conference, June 1999, pp 1705-1711.

9. Chen, X, J.Yi, G.Qi, and F.Liu, "Electroless nickel bath for wafer bumping: Influence of additives", Proceedings of the International Symposium on Electronic Materials and Packaging 2000, November 2000, pp12-17.

10. Liu, C, Hutt, D.A, Whalley, D.C, Conway, P.P, Mannan, S.H, "Under Bump Metallisation of Fine Pitch Flip-chip Using Electroless Nickel Deposition", Journal of Electronics Manufacturing, Vol.10, No. 3, 2000, pp 161-170.

11. Thomas, T, T.Teutsch, and E. Zakel, "Low cost flip chip bumping", Proceedings of the International Symposium on Electronic Materials and Packaging 2000, November 2000, pp72-78.

12. Chow, Y.M, W.M.Lau, R.E.Schetty, and Z.S.Karim, "Feasibility and reliability study on the electroless nickel bumping and stencil solder printing for low cost flip chip electronic packaging", Proceedings of the International Symposium on Electronic Materials and Packaging 2000, November 2000, pp79-85.

13. Coskina, P, U.Oestermann, A.Ostmann, and R.Aschenbrenner, and H.Reichl, "A new stencil performance for high density printing", Proceedings of $13^{\text {th }}$ European Microelectronics and Packaging Conference \& Exhibition, May-June, 2001, pp.42-47.
14. Pan, P, G.L.Tonkay, and R.H.Storer, "Critical variables of solder paste stencil printing for micro-BGA and fine pitch QFP”, Proceedings of 1999 IEMT symposium, October 1999, pp94-101.

15. Adriance, J.H, M.A.Whitemore, and J.D. Schake, "Bumping of silicon wafers by stencil printing", Proceedings of 1999 IEMT symposium, October 1999, pp313-319.

16. Wong, C.K, and D.J.Waldorf, "Plastic solder paste stencil for surface mount technology", Proceedings of 2000 IEMT symposium, October 2000, pp294-303.

17. Zou, L.C, M. Dusek, M. Wickham, C. Hunt, "Fine pitch stencil printing using enclosed printing systems", Soldering \& Surface Mount Technology, 15/1 (2003):43:49.

18. Ezawa, H, M. Seto, M. Miyata, H. Tazawa, "Polymer film deposition with pitch openings by stencil printing", Microelectronics Reliability, 43 (2003):473-479.

19. Durairaj, R, G.J. Jackson, N.N. Ekere, G. Glinski, C. Bailey, "Correlation of solder paste rheology with computational simulation of the stencil printing process", Soldering \& Surface Mount Technology, 14/1 (2002):11:17.

20. He, D.A, N.N. Ekere, B. Salam, R. Durairaj, G. Jackson, "Monte Carlo study of solder paste microstructure and ultrafine stencil printing", Journal of materials Science: Materials in Electronics, 14 (2003):501-506.

21. Hutt, D.A, C. Liu, P.P. Conway, D.C. Whalley, and S.H. Mannan, "Electroless nickel bumping of aluminum bondpads Part 1: surface pre-treatment and activation", IEEE Transactions on Components and Packaging Technologies, 25(1) March (2002):87-97.

22. Hutt, D.A, C. Liu, P.P. Conway, D.C. Whalley, and S.H. Mannan, "Electroless nickel bumping of aluminum bondpads Part 2: Electroless nickel plating", IEEE Transactions on Components and Packaging Technologies, 25(1) March (2002): 98-105.

23. Glinski, G.P, C. Bailey, K.A. Pericleous, "A non-Newtonian computational fluid dynamics study of the stencil printing process", Proceedings: Institute of Mechanical Engineers, Part C, 215 (2001): 437-446.

24. Durairaj, R, T.A. Nguty; N.N. Ekere, "Critical factors affecting paste flow during the stencil printing of solder paste", Soldering \& Surface Mount Technology, 13/2 (2001):30-34.

25. Huang, X, Lee, S.W.R., Yan, C, Hui, S, "Characterisation and Analysis on the Solder Ball Shear Testing Conditions," Proc $51^{\text {st }}$ Electronic Components \& Technology Conference, Orlando, FL, May 2001, pp.1065-1071. 